\title{
Growth and Sugar Metabolism of a Thermoacidophilic Iron-oxidizing Mixotrophic Bacterium
}

\author{
By ANN P. WOOD* AND DON P. KELLY \\ Department of Environmental Sciences, University of Warwick, Coventry CV4 7AL, UK
}

(Received 13 January 1984)

\begin{abstract}
Mixotrophic growth of a thermoacidophilic iron-oxidizing, facultatively autotrophic bacterium is described. Rapid growth with sucrose, fructose, glucose and ribose required the concurrent oxidation of ferrous iron, which, it was concluded, provided most of the energy required for biosynthesis. Specific iron oxidation rate during growth and biomass production depended on the sugar supplied. About $20 \%$ of the cell carbon was obtained from $\mathrm{CO}_{2}$-fixation during growth on glucose. The presence of ribulosebisphosphate carboxylase indicated this to be fixed by the Calvin cycle. The kinetics and inhibition of glucose transport indicated uptake by diffusion and by energy-dependent processes. Sensitivity to fluoride indicated the possible involvement of a phosphoenolpyruvate-phosphotransferase system. Radiorespirometry, using specifically labelled glucose molecules, demonstrated that glucose was oxidized by the oxidative pentose phosphate cycle with further oxidation of glyceraldehyde 3-phosphate by means of the tricarboxylic acid cycle. Dehydrogenases for glucose 6-phosphate and 6-phosphogluconate were present but 6-phosphogluconate dehydratase and 2-keto-3-deoxy-6-phosphogluconate aldolase were not detected in cell-free extracts, showing absence of the Entner-Doudoroff pathway.
\end{abstract}

\section{INTRODUCTION}

Natural and man-made environments in which metal sulphide leaching occurs are acidic (pH 1-3) and self-heat because of the exothermic oxidation processes. These and other natural geothermal habitats have been the source of diverse isolates of moderately thermoacidophilic eubacteria capable of growing at the expense of iron- or sulphide mineral-oxidation (Le Roux et al., 1977; Golovacheva \& Karavaiko, 1977, 1979; Brierley \& Lockwood, 1977; Brierley, 1978; Brierley et al., 1978, 1980). At least some of these isolates were capable of autotrophic growth, using the Calvin cycle for $\mathrm{CO}_{2}$-fixation, but greatest activity was reported when a source of organic carbon as well as oxidizable iron or minerals was supplied (Golovacheva \& Karavaiko, 1977; Norris et al., 1980; Marsh \& Norris, 1983; Wood \& Kelly, 1983). Virtually nothing is known, however, about the relationship of inorganic substrate oxidation to organic carbon and $\mathrm{CO}_{2}$-assimilation. Little is known of the extent to which mixotrophic carbon and energy metabolism occurs or of the mechanisms by which sugars are metabolized.

We have characterized the mechanism of glucose metabolism and mixotrophic growth on several sugars and ferrous iron by a newly isolated thermoacidophile.

\section{METHODS}

Organism and growth conditions. The isolation of strain ALV, its culture media, culture conditions and measurement of growth and iron oxidation have been described previously (Marsh \& Norris, 1983; Wood \& Kelly, 1983). This organism may be closely related to Sulfobacillus thermosulfidooxidans (Golovacheva \& Karavaiko, 1979).

Abbreviations: EMP, Embden-Meyerhof-Parnas; FCCP, carbonyl cyanide p-trifluoromethoxyphenylhydrazone; KDPG, 2-keto-3-deoxy-6-phosphogluconate; PEP, phosphoenolpyruvate; PTS, phosphotransferase system; RuBP, ribulose bisphosphate; RuBPC, ribulosebisphosphate carboxylase; TCA, tricarboxylic acid; TTFB, 4,5,6,7-tetrachloro-2'-trifluoromethylbenzimidazole; OPP, oxidative pentose phosphate. 
${ }^{14} \mathrm{C}$-labelled substrate incorporation. Incorporation of ${ }^{14} \mathrm{C}$ was measured as previously described (Wood \& Kelly, 1983). In mixotrophic growth experiments, ${ }^{14} \mathrm{C}$-labelled sugars were supplied as appropriate volumes of $0.1 \mathrm{M}$ aqueous solution added to $100 \mathrm{ml}$ cultures in $250 \mathrm{ml}$ conical flasks.

Preparation of cell suspensions. Strain ALV, adapted to grow without reduced sulphur, was grown at $50{ }^{\circ} \mathrm{C}$ on $50 \mathrm{mM}^{-\mathrm{FeSO}_{4}}$ with $1 \mathrm{mM}$-glucose. The cultures (4-61) were harvested by centrifuging at $23000 \mathrm{~g}$ for $15 \mathrm{~min}$ at $10^{\circ} \mathrm{C}$ and washed in dilute $\mathrm{H}_{2} \mathrm{SO}_{4}, \mathrm{pH} 2 \cdot 0$. Organisms were resuspended in $\mathrm{K}_{2} \mathrm{HPO}_{4}\left(0 \cdot 1 \mathrm{~g} \mathrm{l}^{-1}\right)$, adjusted to pH $2 \cdot 0$ with $\mathrm{H}_{2} \mathrm{SO}_{4}$ for transport studies or radiorespirometry, and in $0 \cdot 1 \mathrm{M}$-PIPES buffer, $\mathrm{pH} 7 \cdot 0$, for preparation of cell-free extracts with the French pressure cell (Wood et al., 1977).

Radiorespirometry. Details of radiorespirometry substrates and apparatus for collection and measurement of ${ }^{14} \mathrm{CO}_{2}$ have been described previously (Wood et al., 1977). Radiorespirometry studies were carried out at $47^{\circ} \mathrm{C}$. Carbonic anhydrase was unnecessary to assist rapid release of $\mathrm{CO}_{2}$ at the $\mathrm{pH}$ value used and was omitted from the reaction mixture. Initial experiments included $\mathrm{FeSO}_{4}(20 \mathrm{~mm})$ in the reaction mixture, but it was found to be unnecessary for glucose oxidation and was subsequently omitted.

Enzyme assays. All enzymes were assayed at $50^{\circ} \mathrm{C}$. Methods for most enzyme assays were as described previously (Wood et al., 1977; Wood \& Kelly, 1980). Ribulosebisphosphate carboxylase (RuBPC) assay followed the method of Smith et al. (1980): organisms were collected on membrane filters (Whatman WCN, $25 \mathrm{~mm}$, $0.45 \mu \mathrm{m}$ pore size) to give $0.25-0.55 \mathrm{mg}$ dry wt per filter. These were immersed in $0.4 \mathrm{ml} 5 \%(\mathrm{v} / \mathrm{v})$ Triton X-100 in scintillation vials at $20^{\circ} \mathrm{C}$ for $20 \mathrm{~min}$. The standard $\left[{ }^{14} \mathrm{C}\right]$ bicarbonate reaction mixture $(0.9 \mathrm{ml})$ was added and incubation continued at $47^{\circ} \mathrm{C}$ for $10 \mathrm{~min}$ to activate the enzyme. Reaction was initiated with $0 \cdot 3 \mathrm{ml} 10 \mathrm{mM}-\mathrm{RuBP}$. Controls without RuBP and zero-time blanks were also run. Reaction was terminated after $15 \mathrm{~min}$ by adding $3 \mathrm{ml}$ $5 \%(\mathrm{v} / \mathrm{v})$ acetic acid in methanol. The samples were evaporated to dryness at $60^{\circ} \mathrm{C}$ and the residues taken up in $1 \mathrm{ml}$ water. Fixed ${ }^{14} \mathrm{C}$ was counted using $10 \mathrm{ml}$ 'Aqualuma Plus' scintillant (LKB). Specific activity of ${ }^{14} \mathrm{CO}_{2}$ was measured by counting aliquots of standard $\left[{ }^{14} \mathrm{C}\right]$ bicarbonate reaction mixture in $2 \mathrm{ml}$ ethanolamine/methoxyethanol $(3: 7, \mathrm{v} / \mathrm{v})$ and $10 \mathrm{ml}$ scintillant.

Glucose transport. $\left[{ }^{14} \mathrm{C}\right]$ Glucose transport by cell suspensions was measured at $47^{\circ} \mathrm{C}$ by the membrane filter method (Wood \& Kelly, 1982).

Chemicals. ${ }^{14} \mathrm{C}$-labelled sugars and carbonate were obtained from Amersham and New England Nuclear as described previously (Wood et al., 1977; Wood \& Kelly, 1980). [3-14 C]Glucose, manufactured by New England Nuclear, was a gift from Dr C. H. Wang (University of Oregon, USA). FCCP and TTFB were gifts from Dr M. D. Partis (GCRI, Littlehampton, UK).

\section{RESULTS}

\section{Growth on sugars in the absence of reduced sulphur compounds}

Previous work with thermoacidophiles of this type showed that autotrophic and mixotrophic cultures on ferrous iron required a reduced sulphur compound (thiosulphate, tetrathionate or an organic substance such as glutathione) as a growth factor (Brierley et al., 1978, 1980; Marsh \& Norris, 1983; Wood \& Kelly, 1983). Autotrophic growth of Sulfobacillus without added reduced sulphur was apparently observed by Golovacheva \& Karavaiko (1977). We subsequently found that strain ALV could use sulphate as sole sulphur source in a medium containing ferrous iron supplemented with $1 \mathrm{~mm}$-trisodium citrate (A. P. Wood and D. P. Kelly, unpublished), but that reduced sulphur was still required for autotrophic growth on iron. This citrate-adapted culture could also grow mixotrophically without added reduced sulphur when provided with other carbon compounds including glutamate, acetate, acetamide and succinamide. Ready transfer was then possible between media containing glucose, sucrose, fructose, and ribose as carbon sources. These cultures on glucose, fructose and sucrose were subsequently subcultured for up to 100 generations. Exponential rates of iron oxidation indicated doubling times of $3-5 \mathrm{~h}$ (Fig. 1). These rates were similar to those previously reported for cultures using reduced sulphur (Wood \& Kelly, 1983) and were not increased by the addition of 0.05 mm-tetrathionate. Growth, expressed as specific iron oxidation rate, was similar with 1-4 mM-sugars and was significantly faster with fructose or sucrose than with glucose or ribose (Fig. 1). As iron oxidation was exponential, it clearly reflected the activity of exponentially growing organisms, thus demonstrating proportionality of growth and iron oxidation. The relationship of biomass production to iron oxidation could not be deduced directly from these simple observations.

\section{Incorporation of ${ }^{14} \mathrm{CO}_{2}$ and $\left[\mathrm{U}-{ }^{14} \mathrm{C}\right]$ glucose during mixotrophic growth on iron}

Incorporation of carbon from $\mathrm{CO}_{2}$ and glucose separately labelled with ${ }^{14} \mathrm{C}$ was used to determine the proportion of cell carbon derived from each substrate during mixotrophic growth. 


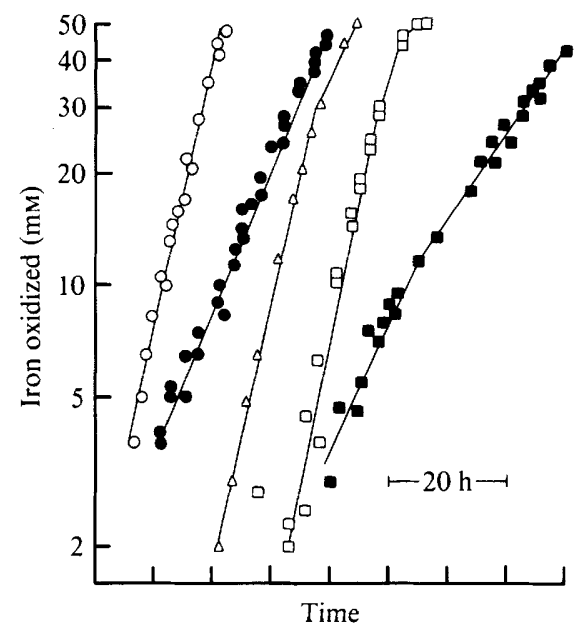

Fig. 1. Specific rates of iron oxidation for strain ALV growing with sucrose $(O)$, glucose $(\Theta)$, fructose $(\triangle)$, glucose + fructose $(\square)$ and ribose $(\square)$. Mean specific growth rates $\left(\mu_{\mathrm{Fe}}, \mathrm{h}^{-1} \pm \sigma_{n-1}\right.$, from $6-10$ determinations) were $0 \cdot 20 \pm 0.02$ ( $1 \mathrm{mM}$-sucrose) $; 0.14 \pm 0.02(1,2$ or $4 \mathrm{mM}$-glucose) $; 0.18 \pm 0.02(1,2$ or $4 \mathrm{~mm}$-fructose); $0 \cdot 17 \pm 0.02$ (glucose + fructose, $1 \mathrm{mM}$ each); $0.065 \pm 0.010$ (1 mM-ribose). The relative time scale is indicated on the $x$ axis: one division $=10 \mathrm{~h}$.
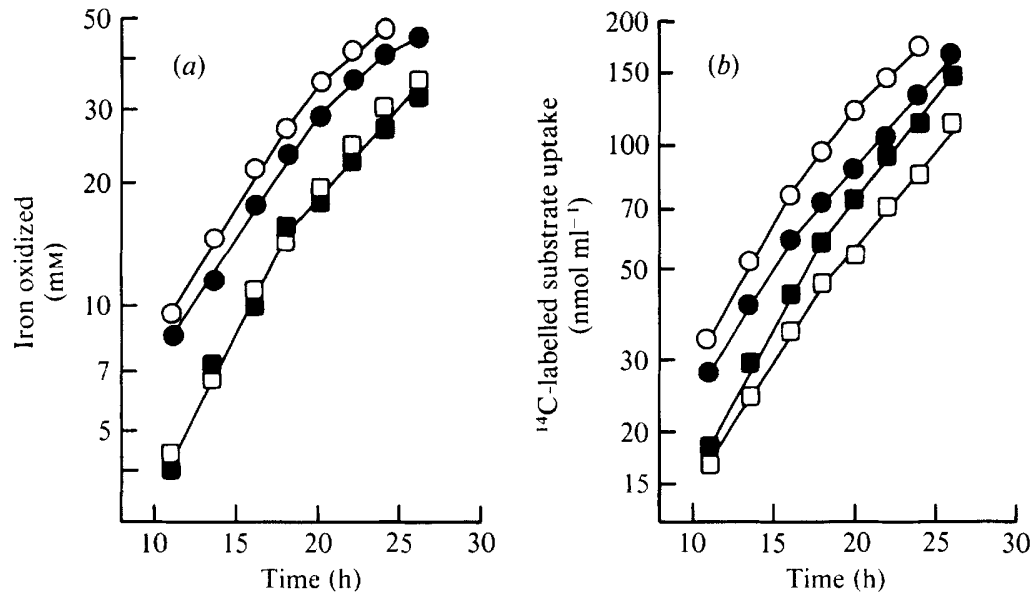

Fig. 2. Iron oxidation and substrate assimilation by strain ALV growing on $50 \mathrm{mM}^{-\mathrm{FeSO}_{4}}$ with $1 \mathrm{~mm}$ [U-1 ${ }^{14} \mathrm{C}$ ]glucose in a sealed flask $(\mathrm{O})$; a flask open to air $(\mathrm{O})$; or on $1 \mathrm{mM}$-glucose plus $5 \mathrm{~mm}-\mathrm{NaHCO}_{3}$ in sealed flasks and labelled with either $\left[\mathrm{U}^{-14} \mathrm{C}\right] \mathrm{glucose}(\square)$ or $\mathrm{NaH}^{14} \mathrm{CO}_{3}(\square)$. (a) $\mathrm{FeSO}_{4}$ oxidation; (b) ${ }^{14} \mathrm{C}$ assimilation.

As glucose and $\mathrm{CO}_{2}$ were the only carbon substrates available, the sum of ${ }^{14} \mathrm{C}$ incorporation from them was a direct measure of biomass production. This could be correlated with the concurrent iron oxidation and used to calculate growth yield in terms of carbon fixed (mol $\mathrm{FeSO}_{4}$ oxidized) ${ }^{-1}$.

Growth rates were very similar when expressed either as iron oxidation or ${ }^{14} \mathrm{C}$ incorporation relative to time (Fig. 2). Rates were little affected by providing cultures with additional bicarbonate or by limiting access to atmospheric $\mathrm{CO}_{2}$ in sealed flasks (Fig. 2). Differential plots of ${ }^{14} \mathrm{C}$ incorporation relative to iron oxidized, under the various growth conditions detailed in Fig. 2, enabled assessment of both growth yield and of the significance of $\mathrm{CO}_{2}$ as an intermediate for glucose incorporation (Fig. $3 a$ ). Carbon from ${ }^{14} \mathrm{CO}_{2}$ contributed about $18.5 \%$ of the total carbon assimilated during growth on glucose $+\mathrm{CO}_{2}$ (Fig. 3a, Table 1). Total biosynthesis indicated a yield of $264 \mathrm{mg}$ carbon ( $\mathrm{mol} \mathrm{FeSO}_{4}$ oxidized) ${ }^{-1}$. Expression of yield in these terms is valid as glucose and $\mathrm{CO}_{2}$ incorporation virtually ceased when no ferrous iron 


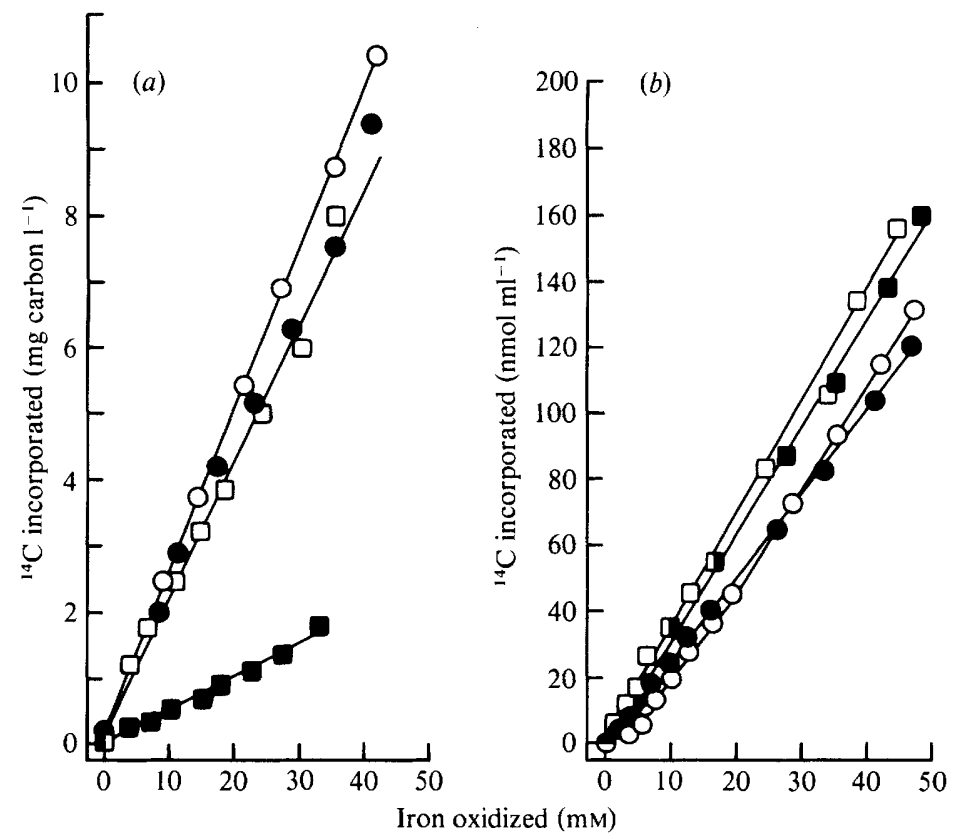

Fig. 3. Relationship of $\mathrm{FeSO}_{4}$ oxidation and ${ }^{14} \mathrm{C}$ assimilation from glucose or $\mathrm{CO}_{2}$ by strain $\mathrm{ALV}$. (a) ${ }^{14} \mathrm{C}$ incorporation from $1 \mathrm{mM}-\left[\mathrm{U}-{ }^{14} \mathrm{C}\right]$ glucose by cultures growing in a sealed flask containing air only (O); in a flask open to air (O); in a sealed flask supplemented by $5 \mathrm{~mm}-\mathrm{NaHCO}_{3}(\square)$; and ${ }^{14} \mathrm{C}$ incorporation from ${ }^{14} \mathrm{CO}_{2}$ by a culture in a sealed flask with $1 \mathrm{~mm}$-glucose and $5 \mathrm{mM}-\mathrm{NaH}^{14} \mathrm{CO}_{3}(\square)$. (b) Incorporation of ${ }^{14} \mathrm{C}$ from $\left[6-{ }^{-14} \mathrm{C}\right]$ glucose $(\square, \square)$ or $\left[1-{ }^{14} \mathrm{C}\right]$ glucose $(O, O)$ in the cultures growing in sealed flasks containing only air $(\square, \bigcirc)$ or supplemented with $6 \%(v / v) \mathrm{CO}_{2}(\square, 0)$.

Table 1. Incorporation of ${ }^{14} \mathrm{CO}_{2}$ and $\left[U^{-14} \mathrm{C}\right]$ glucose during growth of strain $\mathrm{ALV}$ with $50 \mathrm{mM}^{-} \mathrm{FeSO}_{4}$ and $1 \mathrm{m \textrm {M } - g l u c o s e}$

\begin{tabular}{|c|c|c|c|c|}
\hline \multirow[b]{2}{*}{ Growth conditions } & \multirow[b]{2}{*}{$\begin{array}{l}\text { Doubling } \\
\text { time } \\
(\mathrm{h})^{*}\end{array}$} & \multicolumn{2}{|c|}{${ }^{14} \mathrm{C}$-labelled substrate incorporated } & \multirow[b]{2}{*}{$\begin{array}{c}\text { Total carbon } \\
\text { assimilated }[\mathrm{mg} \\
\left.(\mathrm{mol} \mathrm{Fe} \text { oxidized })^{-1}\right]\end{array}$} \\
\hline & & $\begin{array}{c}{[\mathrm{mmol}} \\
\left.(\mathrm{mol} \mathrm{Fe} \text { oxidized })^{-1}\right]\end{array}$ & $\begin{array}{c}\text { [mg carbon } \\
(\text { mol Fe oxidized })^{-1} \text { ] }\end{array}$ & \\
\hline (a) $\left[{ }^{14} \mathrm{C}\right]$ Glucose $+\mathrm{CO}_{2}$ & $3 \cdot 8$ & $2 \cdot 99$ & $215 \cdot 3\}$ & $264 \cdot 0$ \\
\hline (b) Glucose $+{ }^{14} \mathrm{CO}_{2}$ & $3 \cdot 8$ & 4.06 & $48 \cdot 7\}$ & $204 \cdot 0$ \\
\hline (c) $\left[{ }^{14} \mathrm{C}\right]$ Glucose (open) & $5 \cdot 1$ & 3.06 & $220 \cdot 1$ & - \\
\hline (d) $\left[{ }^{14} \mathrm{C}\right]$ Glucose (sealed) & $4 \cdot 7$ & 3.53 & $254 \cdot 2$ & - \\
\hline
\end{tabular}

* From specific rate of iron oxidation $\left(\mu_{\mathrm{Fe}}\right.$; see Fig. $\left.2 a\right)$.

remained in the cultures. Incorporation of ${ }^{14} \mathrm{C}$ from glucose was greatest by cultures in sealed flasks without added bicarbonate, in which little atmospheric $\mathrm{CO}_{2}$ was available (Fig. $3 a$ ). Consequently, ${ }^{14} \mathrm{CO}_{2}$ from glucose oxidation would have been refixed. Cultures open to air or supplemented with bicarbonate incorporated about $15 \%$ less ${ }^{14} \mathrm{C}$ from glucose (Table 1).

Mass balance estimations for cultures growing on glucose under various conditions (Table $2 a$ ) showed that about $75 \%$ of the initial $1 \mathrm{~mm}$-glucose remained unchanged in the culture medium at the end of growth and very little glucose was lost as $\mathrm{CO}_{2}$. The ratio of ${ }^{14} \mathrm{C}$ incorporated to that presumed oxidized to $\mathrm{CO}_{2}$ was $2: 1$ (Table $2 a$ ). Loss of fixed ${ }^{14} \mathrm{CO}_{2}$ from the bacteria into the medium was insignificant. 


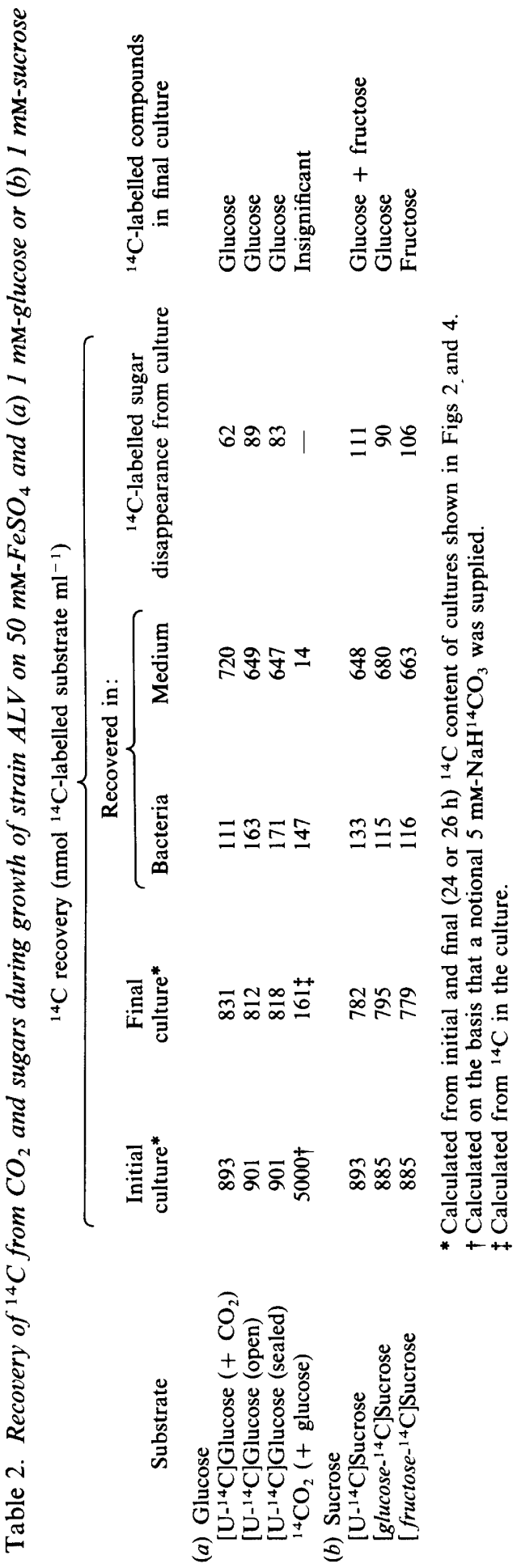



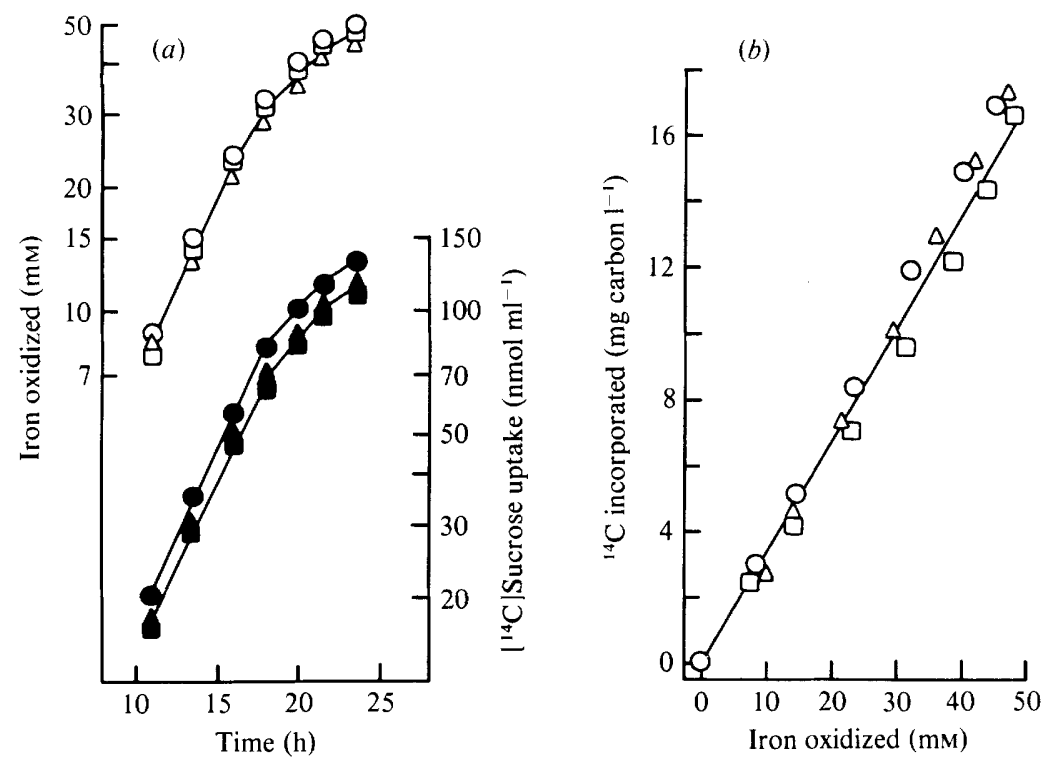

Fig. 4. Growth and ${ }^{14} \mathrm{C}$ incorporation by strain $\mathrm{ALV}$ growing on ${ }^{14} \mathrm{C}$-labelled sucrose. (a) $\mathrm{FeSO}_{4}$ oxidation $(O, \square, \triangle)$ and ${ }^{14} \mathrm{C}$ incorporation $(\boldsymbol{O}, \boldsymbol{\square}, \mathbf{\Delta})$ by cultures growing with $1 \mathrm{~mm}-\left[\mathrm{U}-{ }^{14} \mathrm{C}\right]$ sucrose $(O, 0)$; [ glucose- $\left.{ }^{-14} \mathrm{C}\right]$ sucrose $(\square, \boldsymbol{\square})$; or $\left[\right.$ fructose $\left.{ }^{-14} \mathrm{C}\right]$ sucrose $(\triangle, \boldsymbol{\Lambda}) .(b){ }^{14} \mathrm{C}$ incorporation relative to iron oxidized for cultures using $\left[\mathrm{U}-{ }^{-14} \mathrm{C}\right]$ sucrose $(\mathrm{O})$; [ glucose $\left.{ }^{-14} \mathrm{C}\right]$ sucrose $(\square)$; or $\left[\right.$ fructose $\left.{ }^{-14} \mathrm{C}\right]$ sucrose $(\triangle)$.

\section{Comparison of incorporation of $\left[1-{ }^{14} \mathrm{C}\right]$ glucose and $\left[6-{ }^{14} \mathrm{C}\right]$ glucose during growth}

Strain ALV was grown in sealed flasks containing air or air with $6 \%(\mathrm{v} / \mathrm{v}) \mathrm{CO}_{2}$ in $50 \mathrm{~mm}$ $\mathrm{FeSO}_{4}$ medium supplemented with glucose labelled in either C-1 or C-6. If the proportion of glucose incorporated was significantly greater than that oxidized, a relatively small difference would be expected in the amount of ${ }^{14} \mathrm{C}$ assimilated from $\mathrm{C}-1$ and $\mathrm{C}-6$. This would contrast with most heterotrophic mechanisms of glucose metabolism, in which $\mathrm{CO}_{2}$ release from $\mathrm{C}-1$ would exceed that from C-6. Relative incorporation of ${ }^{14} \mathrm{C}$ from C-6 and C-1 indicated 3.35 and $2.60 \mathrm{mmol}$ ( $\mathrm{mol} \mathrm{FeSO}{ }_{4}$ oxidized) ${ }^{-1}$ (Fig. $3 b$ ). The slight preference for C-6 was consistent with only limited oxidation of glucose and with preferential release of $\mathrm{CO}_{2}$ from the $\mathrm{C}-1$ position. The addition of $6 \% \mathrm{CO}_{2}$ slightly depressed total ${ }^{14} \mathrm{C}$ incorporation (Fig. $3 b$ ), confirming the limited refixation of $\mathrm{CO}_{2}$ released by glucose oxidation.

\section{Growth on $\left[U-{ }^{14} \mathrm{C}\right]$ sucrose}

Doubling time, measured as $\mu_{\mathrm{Fe}}$ or ${ }^{14} \mathrm{C}$ incorporation from sucrose, was about $3.5 \mathrm{~h}$ (Fig. $4 \mathrm{a}$ ). Comparison of ${ }^{14} \mathrm{C}$ incorporation (relative to iron oxidized) from sucrose labelled in the whole molecule or specifically in the glucose or fructose moiety showed that no discrimination was made in incorporation of the two component hexoses. Although chemical hydrolysis of sucrose occurred during the experiment, the lack of discrimination indicated sucrose to be incorporated intact, as non-equivalent incorporation of glucose and fructose was observed when mixtures were provided (see following section). Analysis of the medium at the cessation of growth (Table $2 b$ ) demonstrated that approximately equal amounts of ${ }^{14} \mathrm{C}$ had been incorporated into the bacteria and lost from the culture, presumably as ${ }^{14} \mathrm{CO}_{2}$, but that $75 \%$ of the ${ }^{14} \mathrm{C}$ remained in the solution.

\section{Comparative incorporation of ${ }^{14} \mathrm{C}$-labelled sugars by strain $A L V$ pregrown on glucose,} fructose or sucrose

Organisms previously grown on glucose incorporated considerably more ${ }^{14} \mathrm{C}$ from fructose than from glucose when inoculated into media containing one or other sugar (Fig. 5a). Overall incorporation $\left[\mathrm{mmol}\right.$ hexose $\left(\mathrm{mol} \mathrm{FeSO}_{4} \text { oxidized) }\right)^{-1}$ ] was equivalent to $2 \cdot 10$ for glucose and 


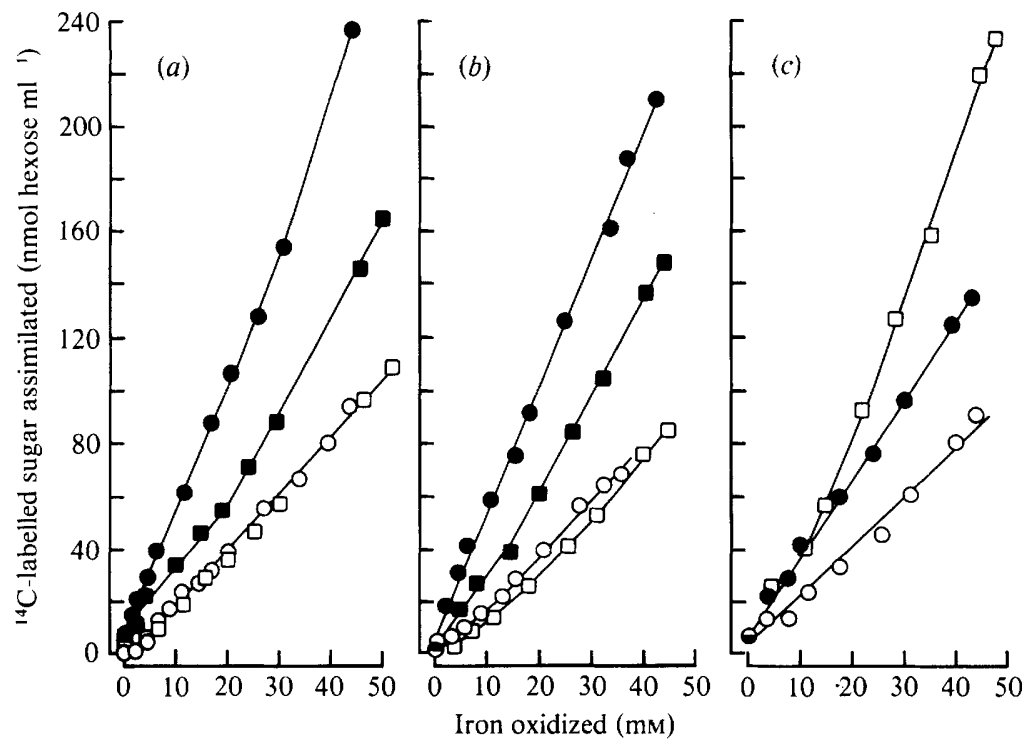

Fig. 5. Comparative incorporation of ${ }^{14} \mathrm{C}$ from glucose, fructose and sucrose, alone or in mixture, by strain ALV cultures after inoculation with bacteria previously grown on various sugars. $(a)$ and $(b),{ }^{14} \mathrm{C}$ incorporation relative to iron oxidized in cultures growing on $\left[\mathrm{U}-{ }^{14} \mathrm{C}\right]$ fructose $(\mathrm{O})$ or $\left[\mathrm{U}-{ }^{14} \mathrm{C}\right] \mathrm{glucose}$ (O) alone or on mixtures of $\left[\mathrm{U}-{ }^{14} \mathrm{C}\right]$ fructose + unlabelled glucose $(\mathbf{a})$ or $\left[\mathrm{U}-{ }^{14} \mathrm{C}\right] \mathrm{glucose}+$ unlabelled fructose $(\square)$ by cultures inoculated with organisms previously maintained on $(a)$ glucose, $(b)$ fructose. (c) ${ }^{14} \mathrm{C}$ incorporation relative to iron oxidized in cultures growing on $\left[\mathrm{U}^{-14} \mathrm{C}\right]$ sucrose $(\square)$, [U$\left.{ }^{14} \mathrm{C}\right]$ fructose + unlabelled glucose $(O)$, or $\left[\mathrm{U}-{ }^{14} \mathrm{C}\right]$ glucose + unlabelled fructose $(O)$ and previously grown on unlabelled sucrose. All incorporation values are expressed as nmol hexose incorporated (ml culture $)^{-1}$, counting each sucrose as two hexose molecules.

5.73 for fructose. In media containing both sugars, glucose considerably depressed fructose assimilation (to 3.28) but fructose had no significant effect on glucose assimilation (Fig. $5 a$ ). This meant that cultures growing with $1 \mathrm{~mm}$ each of glucose and fructose incorporated a total of $5.5 \mathrm{mmol}$ hexose (mol $\mathrm{FeSO}_{4}$ oxidized) ${ }^{-1}$ or the same amount as incorporated from fructose as sole substrate.

Essentially similar results were obtained when the organisms were pregrown on fructose (Fig. $5 b)$. Relative incorporation rates [ $\mathrm{mmol}$ hexose $\left(\mathrm{mol} \mathrm{FeSO}_{4}\right.$ oxidized) ${ }^{-1}$ ] were 4.89 and 1.84 for fructose and glucose alone, but 3.29 and 1.89 for fructose and glucose, respectively, from mixtures. $\mathrm{CO}_{2}$ fixation during growth on fructose alone or mixed with glucose was not determined. $\mathrm{CO}_{2}$ contributed no more than $20 \%$ of the total carbon during growth on glucose, so it can be concluded that growth yield relative to iron oxidation was considerably enhanced when fructose was used.

Organisms previously grown on sucrose also incorporated fructose more rapidly than glucose when provided with both sugars (Fig. $5 c$ ). Their incorporation of $\left[\mathrm{U}-{ }^{14} \mathrm{C}\right]$ sucrose was equivalent to about $5.6 \mathrm{mmol}$ (mol $\mathrm{FeSO}_{4}$ oxidized) ${ }^{-1}$, compared to 2.9 and 2.2 for fructose and glucose, respectively. As each sucrose molecule is equivalent to two hexoses, total carbon incorporation from sucrose slightly exceeded that from fructose and glucose.

\section{Uptake of glucose}

Washed suspensions of glucose-grown strain ALV exhibited concentration-dependent rates of uptake of $\left[\mathrm{U}-{ }^{14} \mathrm{C}\right]$ glucose over the range $3-264 \mu \mathrm{M}$. Uptake rates using concentrations of 150 $260 \mu \mathrm{M}$ were indicative of passive diffusion, as Lineweaver-Burk plots of the reciprocals of rates against reciprocals of concentration extrapolated linearly to zero. Over the lower range of concentration $(3-100 \mu \mathrm{M})$, Lineweaver-Burk plots indicated a high affinity, low $V_{\max }$ uptake system with a $K_{\mathrm{s}}$ of $5.4 \mu \mathrm{M}$ and $V_{\max }$ of $8.7 \mathrm{nmol} \mathrm{min}^{-1}(\mathrm{mg} \text { organism protein })^{-1}$. 
Table 3. Effect of inhibitors on the uptake of $\left[U-{ }^{14} C\right]$ glucose $(132 \mu \mathrm{M})$ by strain $A L V$

$\begin{array}{llc}\text { Inhibitor } & \begin{array}{c}\text { Concn } \\ (\mathrm{mM})\end{array} & \begin{array}{c}\text { Percentage inhibiti } \\ \text { during } 15 \mathrm{~s} \text { in }\end{array} \\ \text { None } & - & 0 \\ \mathrm{NaF} & 10 & 13 \cdot 0 \\ & 30 & 55 \cdot 0 \\ \mathrm{KCN} & 50 & 93 \cdot 9 \\ \text { 2,4-Dinitrophenol } & 2 & 17 \cdot 5 \\ \text { Pentachlorophenol } & 1 & 26 \cdot 4 \\ \text { Ethanol } & 0 \cdot 1 & 24 \cdot 0 \\ \text { FCCP (in ethanol) } & 0.005 & 0 \\ & 0.02 & 65 \cdot 8 \\ \text { TTFB (in ethanol) } & 0.02 & 81 \cdot 7 \\ & 0.10 & 52 \cdot 1 \\ & & 76 \cdot 0\end{array}$

Table 4. Enzymes of carbohydrate metabolism in strain $\mathrm{ALV}$ grown on $\mathrm{FeSO}_{4}(50 \mathrm{~mm})+$ glucose $(1 \mathrm{mM})$ in air

Enzyme

Glucose-6-phosphate dehydrogenase

NAD

NADP

NAD + NADP

6-Phosphogluconate dehydrogenase

NAD

NADP

NAD + NADP

6-phosphogluconate dehydratase + KDPG aldolase

KDPG aldolase

NADH oxidase

NADPH oxidase
Specific activity [nmol $\left.\min ^{-1}(\text { mg protein })^{-1}\right]^{*}$

$83 \cdot 4$

$66 \cdot 2$

$69 \cdot 5$

$32 \cdot 4$

$43 \cdot 1$

$37 \cdot 6$

0

0

$8 \cdot 0$

$2 \cdot 6$

* Protein content of cell extract $=6.6 \mathrm{mg} \mathrm{ml}^{-1}$.

Glucose uptake was inhibited by fluoride and by all the uncoupling agents tested (Table 3). It was not severely inhibited by cyanide or by low concentrations of arsenate (10 mM). The analogue 3-O-methylglucose did not inhibit uptake at $10 \mathrm{~mm}$.

\section{Radiorespirometric studies on glucose oxidation}

Using standard radiorespirometric techniques (Wood et al., 1977), the cumulative release of ${ }^{14} \mathrm{CO}_{2}$ from each of the carbon atoms of glucose (Fig. $6 a$ ) was greatest from C-1 (55 nmol from $66.6 \mathrm{nmol}$ glucose) followed by C-4 (45.5), C-2 (34), then C-6 and C-3 (31.5 and 30.5). From two to five separate determinations for each, mean $\left( \pm \sigma_{n-1}\right)$ values for ${ }^{14} \mathrm{CO}_{2}$ release were $\mathrm{C}-1(52 \cdot 8$ $\pm 3 \cdot 0), C-2(35 \cdot 5 \pm 2 \cdot 4), C-3(32 \cdot 4 \pm 2 \cdot 6)$ and $C-4(42 \cdot 9 \pm 3 \cdot 8)$. The time course of release and the interval release data (Fig. $6 b$ ) demonstrated, however, that the sequence of oxidation was $\mathrm{C}-1>\mathrm{C}-2>\mathrm{C}-3>\mathrm{C}-4>\mathrm{C}-6$, with $\mathrm{C}-4$ release peaking significantly later and lower than that of $\mathrm{C}-1$ and $\mathrm{C}-2$. Release of ${ }^{14} \mathrm{CO}_{2}$ from $\left[1-{ }^{14} \mathrm{C}\right]$ glucose was severely inhibited by fluoride at $1 \mathrm{mM}$ $(98 \%)$ or $25 \mathrm{~mm}(100 \%)$. Ribose $(1 \mathrm{mM})$ had little effect on C-1 release $(56.1 \mathrm{nmol})$ but stimulated C-2 release $(46 \cdot 1 \mathrm{nmol})$ by $36 \%$ over the control (Fig. $6 c$ ).

\section{Enzymes of glucose metabolism in strain ALV}

Glucose-6-phosphate dehydrogenase and 6-phosphogluconate dehydrogenase were demonstrated at high specific activity (Table 4). They appeared to function equally well with $\mathrm{NAD}^{+}$or NADP $^{+}$as coenzymes; lack of additive activity with both coenzymes indicated that they had a 

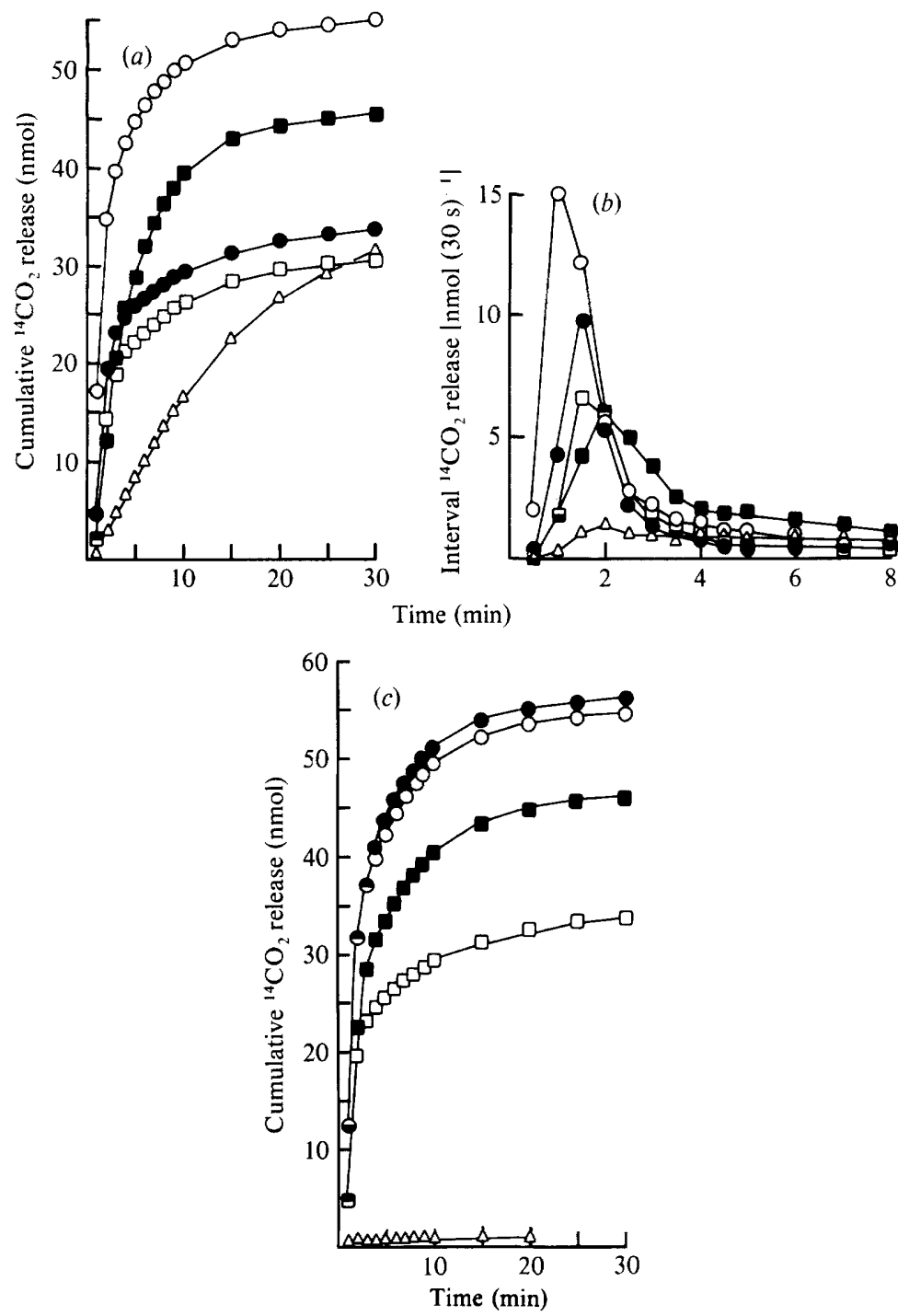

Fig. 6. Radiorespirometry of ${ }^{14} \mathrm{C}$-labelled glucose using strain ALV previously grown on glucose. (a) Cumulative ${ }^{14} \mathrm{CO}_{2}$-release from glucose specifically labelled with ${ }^{14} \mathrm{C}$ in $\mathrm{C}-1(\mathrm{O}), \mathrm{C}-2(\Theta), \mathrm{C}-3(\square)$, $\mathrm{C}-4(\square)$ or $\mathrm{C}-6(\triangle)$ of the carbon-chain; $(b)$ interval release [nmol $(0.5 \mathrm{~min})^{-1}$ ] of ${ }^{14} \mathrm{CO}_{2} ;(c)$ cumulative release of ${ }^{14} \mathrm{CO}_{2}$ from $\mathrm{C}-1$ without any addition $(O)$ and with $1 \mathrm{~mm}$-ribose $(\bigcirc)$ or $1 \mathrm{~mm}$-fluoride $(\Delta)$; and from C-2 alone ( $\square$ ) or in the presence of 1 mM-ribose ( $\square$ ).

non-specific requirement for NAD ${ }^{+}$or NADP ${ }^{+}$. Low levels of NADH and NADPH oxidase were present but no activity could be demonstrated for KDPG aldolase or for 6phosphogluconate dehydratase + KDPG aldolase in the coupled assay used to detect these key enzymes of the Entner-Doudoroff pathway.

Ribulose bisphosphate carboxylase in strain ALV grown under various conditions

When grown autotrophically (Wood \& Kelly, 1983) strain ALV exhibited RuBPC activities of $13.0 \pm 7.7 \mathrm{nmol} \mathrm{CO}$ fixed $\mathrm{min}^{-1}$ (mg dry wt) ${ }^{-1}$ (mean $\pm \sigma_{n-1}$, three determinations). When grown on $\mathrm{FeSO}_{4}$ with glucose or fructose, (1-4 mM), mean specific activity was $9 \cdot 1 \pm 7 \cdot 7$ (10 determinations), indicating that significant activity of the Calvin cycle could have occurred during mixotrophic growth on the sugars. 


\section{Heterotrophic growth of strain ALV on glucose}

Growth on glucose in the absence of $\mathrm{FeSO}_{4}$ using inocula $(10 \%, \mathrm{v} / \mathrm{v})$ from fully-grown cultures on $50 \mathrm{~mm}-\mathrm{FeSO}_{4}+1 \mathrm{~mm}$-glucose was extremely poor in media containing $1 \mathrm{~mm}$-glucose alone or with $1 \mathrm{~mm}$-thiosulphate. Over a $40 \mathrm{~h}$ period only 6 and $14 \mathrm{nmol}$ glucose were assimilated $(\mathrm{ml}$ culture $)^{-1}$, indicating doubling times of up to $18 \mathrm{~h}$. Prolonged incubation ( $>100 \mathrm{~h}$ ) showed growth to continue at this rate, resulting in overall assimilation of about $20 \mu \mathrm{g}$ carbon ml ${ }^{-1}$ after $110 \mathrm{~h}$, equivalent to about a quarter of the initial glucose.

\section{DISCUSSION}

Perhaps the most striking property revealed by this study of the thermoacidophile, currently known only as strain ALV, is its preferentially mixotrophic mode of metabolism. Autotrophic growth of the organism on iron is possible (Wood \& Kelly, 1983), as is slow heterotrophic growth, but the most rapid growth is that seen with mixtures of iron and organic substrates such as the sugars used here. The concerted use of substrates is virtually obligatory under the conditions employed: autotrophic growth requires $\mathrm{CO}_{2}$ concentrations above normal atmospheric levels, and the incorporation of sugars virtually ceases when all oxidizable iron has been consumed, even though ample sugar remains in the culture medium. It seems that carbon is derived in these mixotrophic cultures simultaneously from $\mathrm{CO}_{2}$-fixation by means of the Calvin cycle and from direct assimilation of sugar-carbon. Energy for growth would appear to be provided largely by iron oxidation, as the amount of sugar oxidized by growing cultures is considerably less than that assimilated and the growth yields observed are more like those seen with autotrophic than heterotrophic organisms. It is clear that sugars are assimilated directly, rather than by being oxidized to $\mathrm{CO}_{2}$ to supply additional carbon for the Calvin cycle, since: (a) incorporation of ${ }^{14} \mathrm{C}$ from glucose was not significantly affected by raised $\mathrm{CO}_{2}$ levels as would have occurred if $\mathrm{CO}_{2}$ were an intermediate in glucose assimilation; and (b) carbon was incorporated to a greater extent from the C-6 than from the $\mathrm{C}-1$ of glucose, as would be expected if conventional metabolic pathways operated in the thermophile. Differences in extent of incorporation of different sugars, and consequently differences in yield, probably reflect both the relative rapidity of uptake of different sugars and the level of supplementary energy available from their metabolism.

Uptake of glucose by strain ALV seemed likely to involve an energy-dependent transport process, because of its sensitivity to diverse uncoupling agents. The relative insensitivity of transport to cyanide and arsenate probably rules out the involvement merely of processes requiring high-energy phosphate. Only limited use can be made of the inhibitor data because of possible indirect effects, such as acidification of the cytoplasm following loss of membrane integrity, and lack of knowledge of the action of FCCP and TTFB at acid pH values. The extreme sensitivity of glucose oxidation and uptake to fluoride is possibly indicative of a phosphoenolpyruvate (PEP)-dependent phosphotransferase system (PTS). Fluoride is the classical inhibitor of enolase in the Embden-Meyerhof-Parnas (EMP) sequence, blocking PEP production and hence preventing sugar uptake by the PTS. This finding would suggest that strain ALV employed a mechanism whereby significant PEP synthesis could occur. This might be directly from sugars taken up, using the EMP pathway; from formation using phosphoglycerate generated by the Calvin cycle; or by some more involved route. The mechanism of glucose oxidation was investigated by radiorespirometry and enzyme analysis in order to resolve this point.

The EMP pathway was indicated by radiorespirometry not to be significant, as there was no obvious correlation of release of the C-3 and C-4 atoms of glucose and the amounts of these atoms released were both lower and later than that of C-1 (and in some cases C-2). The lack of correlation of release of C-1 and C-4 similarly indicates little role for the Entner-Doudoroff pathway, which was in fact ruled out by the failure to demonstrate the key enzymes of this pathway in glucose-grown organisms. The radiorespirometry data and the presence of high levels of glucose-6-phosphate dehydrogenase and 6-phosphogluconate dehydrogenase are 


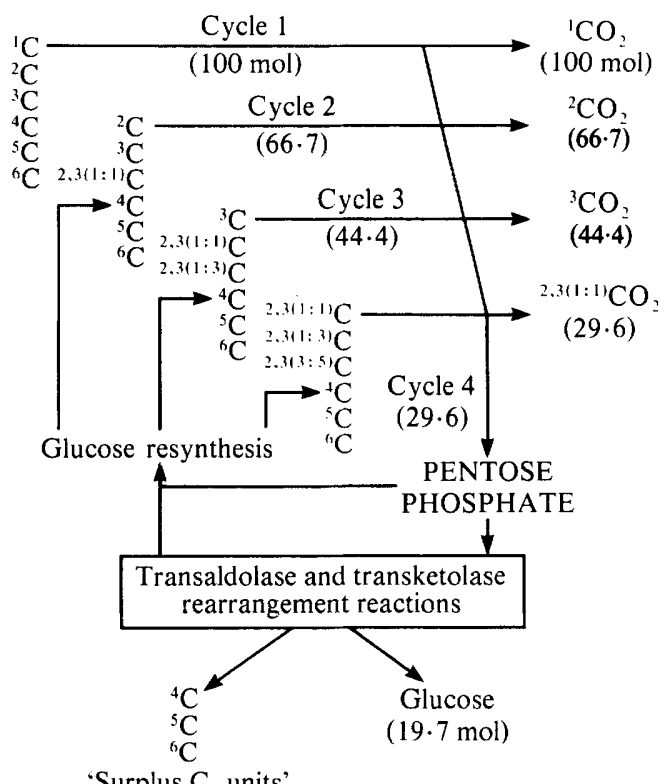

$(80 \cdot 2$ after 4 cycles)

Fig. 7. Sequence and quantities of $\mathrm{CO}_{2}$ release from glucose during oxidation by the oxidative pentose phosphate cycle (calculated after Krebs \& Kornberg, 1957).

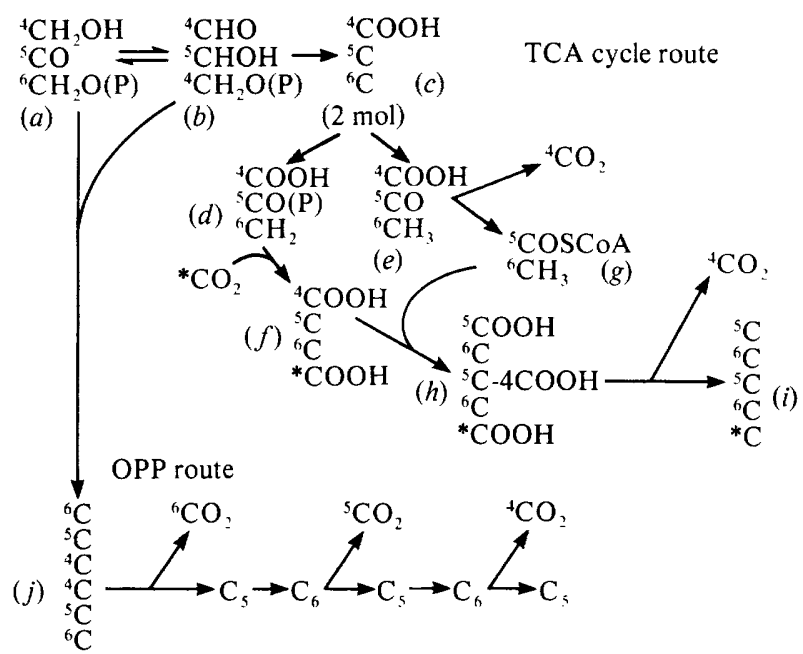

Fig. 8. Origin and sequence of $\mathrm{CO}_{2}$ release by further oxidation of ' $\mathrm{C}_{3}$-units' (glyceraldehyde 3 phosphate) generated by the oxidative pentose phosphate cycle (Fig. 7) through the tricarboxylic acid cycle (TCA cycle route) or by recycling through the oxidative pentose phosphate cycle (OPP route). Intermediates shown are: $(a)$ dihydroxyacetone phosphate; $(b)$ glyceraldehyde 3-phosphate; $(c)$ 3phosphoglycerate; $(d)$ phosphoenolpyruvate; $(e)$ pyruvate; $(f)$ oxaloacetate; $(g)$ acetyl coenzyme A $;(h)$ citrate-isocitrate; (i) 2-oxoglutarate; $(j)$ fructose bisphosphate-glucose 6-phosphate.

wholly consistent with the belief that glucose oxidation proceeded mainly, if not exclusively, by the oxidative pentose phosphate cycle (Krebs \& Kornberg, 1957; Mahler \& Cordes, 1966). The extensive and sequential release of the C-1, C-2 and C-3 of glucose are indicative of this pathway, by the operation of which the C-1, C-2 and C-3 are sequentially released during the first, second and third turns of the cycle (Fig. 7). The fourth turn of the cycle releases C-2 and C-3 
exclusively in the ratio $1: 3$; a fifth turn would also release only C-2 and C-3 in the ratio $4: 12$. From these data (Fig. 7), one can calculate that four turns of the cycle should produce $\mathrm{CO}_{2}$ from the $\mathrm{C}-1, \mathrm{C}-2$ and $\mathrm{C}-3$ of the original glucose in the ratio $100: 81 \cdot 5: 59 \cdot 2$. The observed values were $100: 67: 61$ (with extreme values of 61-76 and 55-69 for C-2 and C-3), which indicate that the oxidative pentose phosphate cycle is likely to have predominated as the primary mechanism of glucose oxidation. Recovery of less than the predicted proportion of $\mathrm{C}-2$ as $\mathrm{CO}_{2}$ could result if pentose were diverted, for example, into nucleotide synthesis. Added ribose stimulated C-2 release (Fig. $6 c$ ) and probably overcame this side-effect, as the ratio of C-1 to C-2 release in its presence was $100: 82$, in close agreement with that predicted if the cycle accounts for all glucose oxidation. Four turns of the cycle produce $80 \mathrm{~mol}^{\text {' }} \mathrm{C}_{3}$ units' per $100 \mathrm{~mol}$ glucose (Fig. 7). These are constituted exclusively from the C-4 to C-6 of the original glucose and must also be further metabolized. Two possibilities exist: (a) the oxidative pentose phosphate route: oxidation by the oxidative pentose phosphate cycle after aldol condensation and formation of glucose (Fig. 8); or (b) the TCA route: conversion to PEP and pyruvate followed by oxidation through the tricarboxylic acid cycle (Fig. 8). By the former, sequential release as $\mathrm{CO}_{2}$ of the C-6, C-5 and C-4 of the original glucose would occur. It is clear from the radiorespirometry data (Fig. 6a,b) that this did not occur. By the TCA route only C-4 would be released by the first two decarboxylations (Fig. 8). Since $80 \mathrm{~mol}$ ' $\mathrm{C}_{3}$ units' could thus be decarboxylated by this route from the original 100 mol glucose, one can predict that the ratio of release of $\mathrm{C}-1$ to $\mathrm{C}-4$ should be $100: 80$. The observed ratio was $100: 81$, indicating the interpretation to be feasible. Since all the ' $\mathrm{C}_{3}$ units' generated (equivalent to $40 \%$ of the initial glucose) would thus pass through PEP during their subsequent metabolism, the organism could generate ample PEP to drive a PEPPTS transport mechanism for glucose and an explanation of the potent inhibitory effect of fluoride is obvious. Clearly, further work is required to elucidate the transport mechanism.

It is apparent that while this organism, and presumably the related and similar strains from other environments, exhibits a number of unusual physiological properties, its basic metabolic processes are in accord with the fundamental unity of prokaryotic biochemistry.

We thank Andrea Filipiuk for technical assistance and Biogen S.A. (Geneva) for financial support of much of this work.

\section{REFERENCES}

BRIERLEY, J. A. (1978). Thermophilic iron-oxidizing bacteria found in copper leaching dumps. Applied and Environmental Microbiology 36, 523-525.

Brierley, J. A. \& LOCKWOOD, S. J. (1977). The occurrence of thermophilic iron-oxidizing bacteria in a copper leaching system. FEMS Microbiology Letters 2, 163-165.

Brierley, J. A., Norris, P. R., Kelly, D. P. \& Le Roux, N. W. (1978). Characteristics of a moderately thermophilic and acidophilic iron-oxidizing Thiobacillus. European Journal of Applied Microbiology and Biotechnology 5, 291-299.

Brierley, C. L., Brierley, J. A., Norris, P. R. \& KELLY, D. P. (1980). Metal-tolerant micro-organisms of hot, acid environments. In Microbial Growth and Survival in Extremes of Environment, pp. 39-51. Edited by G. W. Gould \& J. E. L. Corry. London: Academic Press.

Golovacheva, R. S. \& Karavaiko, G. I. (1977). A new facultative thermophilic Thiobacillus isolated from sulphide ore. In Microbial Growth on $C_{1}$-Compounds, Abstracts of the International Symposium, pp. 108-109. Edited by G. K. Skryatin. Pushchino: USSR Academy of Sciences.
Golovacheva, R. S. \& Karavaiko, G. I. (1979). Sulfobacillus - a new genus of thermophilic sporeforming bacteria. Microbiology (Moscow) 5, 658665.

Krebs, H. A. \& KornberG, H. L. (1957). Energy transformations in living matter. Ergebnisse der Physiologie (biologischen Chemie und experimentellen Pharmakologie) 49, 212-298.

Le Roux, N. W., Wakerley, D. S. \& Hunt, S. D. (1977). Thermophilic thiobacillus-type bacteria from Icelandic thermal areas. Journal of General Microbiology 100, 197-201.

MAHLER, H. R. \& CoRdes, E. H. (1966). Biological Chemistry, pp. 448-454. New York: Harper \& Row.

MARSH, R. M. \& NoRRIS, P. R. (1983). The isolation of some thermophilic, autotrophic iron- and sulphuroxidizing bacteria. FEMS Microbiology Letters 17, 311-315.

Norris, P. R., Brierley, J. A. \& Kelly, D. P. (1980). Physiological characteristics of two facultatively thermophilic mineral-oxidizing bacteria. FEMS Microbiology Letters 7, 119-122. 
Smith, A. L., Kelly, D. P. \& Wood, A. P. (1980). Metabolism of Thiobacillus A2 under autotrophic, mixotrophic and heterotrophic conditions in the chemostat. Journal of General Microbiology 121, 127138.

Wood, A. P., Kelly, D. P. \& Thurston, C. F. (1977). Simultaneous operation of three catabolic pathways in the metabolism of glucose by Thiobacillus A2. Archives of Microbiology 113, 265-274.

Wood, A. P. \& Kelly, D. P. (1980). Carbohydrate degradation pathways in Thiobacillus A2 grown on various sugars. Journal of General Microbiology 120, 333-345.

WooD, A. P. \& Kelly, D. P. (1982). Kinetics of sugar transport by Thiobacillus A2. Archives of Microbiology 131, 156-159.

WooD, A. P. \& Kelly, D. P. (1983). Autotrophic and mixotrophic growth of three thermoacidophilic ironoxidizing bacteria. FEMS Microbiology Letters 20 , 107-112. 